DOI: $10.20472 /$ IAC.2018.035.032

\title{
ALEXANDRA MICHAILIDOU
}

Aristotle University of Thessaloniki, Greece

\section{CHRISTOS VLACHOKOSTAS}

Aristotle University of Thessaloniki, Greece

CHARISIOS ACHILLAS

Technological Educational Institute of Central Macedonia, Greece

NICOLAS MOUSSIOPOULOS

Aristotle University of Thessaloniki, Greece

ELENI FELEKI

Aristotle University of Thessaloniki, Greece

\section{PROMOTING METROPOLITAN AND PERIURBAN AGRICULTURE IN URBAN CLIMATE: THE MADRE PROJECT}

\begin{abstract}
:
The paper presents an approach to put forward Metropolitan and Peri-Urban Agriculture (MPA) in the framework of the MADRE Interreg MED project. The MADRE project, which stands for "Metropolitan Agriculture for Developing and innovative sustainable and Responsible Economy", is designing a methodological framework in order to identify and characterize best practices of MPA in Mediterranean urban conurbations. Aiming at promoting a change process in the metropolitan food supply model, the project will focus on identifying key factors that foster and hamper MPA development according to stakeholders actively involved in MPA, i.e. key players from the quadruple helix involving private actors (farmers, producers and SMEs), civil society (consumers' groups, NGOs), academia and research and public authorities. It should be noted that the MPA innitiatives started to be more and more considered as an important factor for supplying food to the city dwellers, not only in developing countries but also to the metropolitans of the Northern sphere. It can play a crucial role towards encountering climate change by backing up urban ecosystems and urban biodiversity. To address the challenges of MPA, the approach proposed by MADRE partners is to allow a technical and political empowerment of local food production networks of five countries (France, Greece, Italy, Albania and Spain) through the development of a transnational cluster of MPA stakeholders. Such a transnational organization and networking, will allow those actors to foster their eco-innovation capacity (i.e. producers' innovation, consumers' innovation, social innovation, territorial innovation, transnational innovation and academic research) and thus to increase their impact on national, regional and metropolitan policies. Although there are still gaps of knowledge and uncertainties in studying sustainability issues for the three pillars (environment, economy and society) the proposed approach provides a roadmap for decision-makers to put forward urban agriculture in an organized manner. (This paper has received funding from the ERDF through the MED Interreg Programme under Grant Agreement No. 1MED15_1.1_M3_138).
\end{abstract}

\section{Keywords:}

Metropolitan and Peri-urban Agriculture; Decision Making; Methodological Framework; Mediterranean cities; Mediterranean cooperation; food supply chain. 
JEL Classification: Q10, O20, Q01 